\title{
Emotional Behavior with Verbal Violence: Problems and Solutions
}

\author{
Pavel Koller ${ }^{1}$, Petr Darida ${ }^{1}$ \\ ${ }^{1}$ Department of Psychology, Charles University, Czech Republic
}

\begin{abstract}
The aims of the paper is to identify the problems and solutions about emotional behavior with verbal violences. Emotional behavior have a lot of influence on other psychic functions, such as observation, response, thinking, and will. Individuals will be able to make good observations if accompanied by good emotions. Violence is generally classified into four types. According to Lowson, violence is classified into four forms, namely physical abuse is violence perpetrated by someone until someone grows up, emotional abuse occurs when someone is in need of attention but is ignored, verbal abuse occurs when someone giving humiliation, harassment, labeling the pattern of communication, sexual violence (sexual abuse) occurs when someone forces sexual relations. All of the problems in those cases have a discussion and solutions which is avoiding hoax news, instilling habits of good behavior from an early age (parents must be careful when speaking in front of their children), making persuasion advertising a form of strengthening social relations, accustom positive criticism, respect the privacy of others, always use communication tools proportionally, maintaining communication ethics, and avoiding racist and racist content.
\end{abstract}

Keywords: Emotional Behavior, Emotion, Violence

Received: October 17, 2020

Revised: October 29, 2020

Accepted: November 7, 2020

\section{Introduction}

The cause of the inhibition of character formation is mostly due to verbal abuse which has recently become a contemporary phenomenon. This occurs because of a transitional period that raises doubts in them to do or try something that is considered new according to him and determines the behavior pattern that suits him(Martin \& Pear, 2019). The existence of new things in determining character development makes some people vulnerable to several kinds of problems, one of which is related to the surrounding social environment. Supporting factors for violence perpetrated by someone, especially regarding verbal abuse (verbal abus), can also be obtained through family, school, and colleagues. Some views consider the family environment to play the most important role in shaping children's character. One of them is a parent who has experienced unpleasant actions at risk of doing the same thing to their offspring, besides that parents who ignore or do not meet the child's needs because they are busy with their own business so that they cannot give attention or affection to the child, are also at risk of shaping the child's character. which cannot be accepted in the social environment in the long term (Henry \& Stephens, 2013) or following what their parents say can make a person verbally abusive. As another secondary part, the school environment or peers are also a supporting factor for the emergence of verbal violence, what they see through online media or obtained from their surrounding friends who often experience verbal abuse can have a negative impact on others.

Violence is a deliberate act that results in physical injury or mental stress ( Hay \& Meldrum, 2010). Violent behavior is behavior that harms people, themselves physically, emotionally, and sexuality (Livingstone \& Smith, 2014). Verbal abuse or better known as verbal violence 
is "violence against feelings", saying harsh words without touching physical, slanderous words, words that threaten, frighten, insult or exaggerate the mistakes of others is verbal abuse.

Verbal abuse itself is a form of action that uses words or language used to belittle, belittle or slander and hurt others ( Hunt, 2013) this determines the formation of a person's character. Because whether someone is good or bad, whether they are educated or not, it can be seen from the language they use.

According to Rosenthal et al. (2018) verbal violence is "an act that includes rebuking and the delivery of harsh words". In line with that, Lawson said that verbal abuse or verbal violence is "an act of insulting, harassing, and labeling someone in a communication pattern".

The concrete form of verbal violence is "the use of harsh words, abuse of trust, embarrassing people in public and threatening in the form of words". Based on the description above, it can be concluded that verbal violence is a person's verbal action which includes the delivery of harsh words, insults, scolding, scolding, and yelling excessively, as well as giving threats to others.

The impact of verbal abuse is no less dangerous than the impact of physical violence. Verbal abuse does not result in physical damage, but does result in psychological injury to the victim. Therefore, verbal violence is often classified as psychological violence. Verbal abuse can cause psychological instability for the recipient, such as fear, disappointment, low selfesteem, insecurity, heartbreak, frustration, depression (stress), hurt, gloomy, apathy, indifference, confusion, shame, hate, revenge, extreme, radical, aggressive, angry, depressed, crazy, and so on. The general tendency to become victims is the non-dominant group. Children become victims of verbal abuse by their parents, students become victims of verbal abuse from their teachers or seniors, maids become victims of verbal abuse from their employers, subordinates are victims of verbal abuse from their superiors, and other forms of verbal abuse.

\section{Emotions}

According to Bariola et al. (2011) defines emotion as a psycho-physiological symptom that has an effect on perceptions, attitudes and behavior, and manifests in certain forms of expression. Emotions are felt psychophysically because they are directly related to the soul and the physical. When happy emotions explode, it is psychologically satisfying, but physiologically it makes the heart palpitations or the footsteps feel light, also does not feel when screaming with joy, but these things that are mentioned are not specific to everyone in all opportunity. Sometimes people are happy, but shed tears, or the same sadness doesn't bring the same pain.

According to Fontaine et al. (2013), Emotion is included in the affective domain. Emotions have a lot of influence on other psychic functions, such as observation, response, thinking, and will. Individuals will be able to make good observations if accompanied by good emotions. Individuals will also give positive responses to an object when accompanied by positive emotions as well. Conversely, individuals will make observations or negative responses to an object, if accompanied by negative emotions towards the object.

\section{What is Verbal Violence}

Verbal violence is a form of violence. Violence is generally classified into four types. According to Lowson, violence is classified into four forms, namely physical abuse (physical abuse) is violence perpetrated by someone until someone grows up, emotional abuse occurs 
when someone is in need of attention but is ignored, verbal abuse occurs when someone giving humiliation, harassment, labeling the pattern of communication, sexual violence (sexual abuse) occurs when someone forces sexual relations. Often without realizing it, they often hear verbal abuse from family members, friends or people they don't know. Verbal violence in the communication literature can be defined as a form of violence that uses harsh, obscene and insulting words. Verbal violence is currently receiving special attention in communication studies because of its influence or the level of community sensitivity to violent behavior (Dewall et al., 2011). Verbal violence is in the form of communication that contains threats, harsh words, or insults a child's ability which is carried out continuously and results in trauma to the child, feelings of shame, fear, and low self-esteem. Tower (2005) states that verbal violence is violence that is often carried out by those closest to the child, where there are threats or use of harsh words that result or have the potential to result in psychological injury, trauma and other dangerous things. Berkowitz (2003) defines verbal violent behavior as a form of violent behavior or action that is expressed to hurt others, verbal violent behavior can take the form of curses, insults or insults, ridicule, slander and threats through words. Meanwhile, Coons (1986) argues, verbal violence behavior is a communication pattern that contains insults, harsh words or words that abuse children, such as blaming, labeling, or also scapegoating children. Ozgule (2016) states that verbal violence is often referred to as psychic violence, which is an act of violence in the form of speech that results in decreased self-confidence and increased feelings of helplessness.

\section{Forms of Verbal Hardness}

There are various forms of verbal abuse (Tower, 2005), namely: (a) Yelling, namely scolding out loud, among others: (1) to rebuke, is to berate with loud words (2) to judge, is to judge or act as a judge (3) wearing, is to utter bad words. (b) Swearing, namely saying words that are cruel, inappropriate, not good at expressing anger or irritation, among others: (1) denounces, that is, outright insulting (2) spurt, is spraying the words out of the mouth (3) swearing, is speaking profanity to take an oath

c. Giving negative nicknames / labels, namely giving identification marks through the form of words, including: (1) classify, is a classification, grouping based on something that is in accordance with the class (d) Minimizing and abusing children's abilities, namely lowering the child's existence, including: (1) to ignore, is neglect, to waste (2) sideways, is getting rid of towards the edge (3) underestimating, is underestimating (4) lighten, is to make or take lightly (5) to make it easy, is to make it easy, to make it easy (6) is offensive, and despicable.

\section{Characteristics of verbal}

Cater \& Andershed (2014) stated that verbal violence has various characteristics, namely: (a) Verbal violence is very painful and is usually carried out by people closest to the victim who have the opportunity to commit verbal abuse, that is, where the victim ends up believing the perpetrator that something is wrong with him and begins to feel that he is not valuable and that he is the source of the problem. (b) Verbal abuse may occur in invisible behavior (such as: comments, brainwashing with degrading views of the victim). (c) Verbal violence is very manipulative and aims to control the victim, that is, hidden aggression will make the victim confused and ultimately easy to control where the victim finally believes the perpetrator has something. Although the way to do it is subtle (commenting and brain washing), its main purpose is to control and manipulate. (d) Verbal violence causes the victim's self-esteem to decrease without the victim realizing it, and increasingly withdraws from his environment so that the victim will change his behavior and surrender to the behavior whether he realizes it or not. (e) Verbal abuse is unpredictable, in reality sometimes the perpetrator scolds, acts 
harshly, makes harsh comments, puts down or compares with others who are better. (f) Verbal abuse may increase in intensity, frequency and variation. Verbal abuse may be cloaked with jokes that are subtle but through the victim. Verbal abuse may also be followed by physical violence starting with minor accidents such as pushing or throwing objects. Some of the characteristics of verbal abuse above are very clear that the above actions can injure and injure a person both physically and psychologically. Based on the types of violence put forward by (Finkelhor et al., 2011)

Communication violence or verbal abuse speech acts can be divided into four types.

(1) Indirect violent speech acts are verbal violence that does not immediately affect the victim, but through the media or a chain process, for example slander, stigmatization, and stereotyping. (2) Direct violent speech acts are speech acts of violence that directly hit the victim during the communication, such as yelling, cursing, insulting, threatening, mocking, accusing, insulting, belittling, expelling, rejecting, demanding, rebuking, coercing, humiliating, vilifying -disgusting, making fun of, slandering, and blaming. (3) Repressive violent speech acts are speech acts that suppress or intimidate the victim, including forcing, instructing, ordering, threatening, frightening, yelling, scolding, terrorizing, provoking. (4) Alienative violent speech acts are speech acts that intend to alienate, alienate, or even eliminate victims from their community, for example to silence or expel, isolate, discredit, slander, stigmatize, stereotype and discriminate.

\section{Impact of verbal abuse}

Verbal abuse greatly affects the psychological and mental health of the victim. Verbal abuse in children will hurt the feelings of the victim himself even though the wound cannot be seen. However, if the victim experienced verbal abuse from an early age, it is likely that he will carry the scar until he is an adult. The consequences of verbal abuse in childhood according to (Teicher et al., 2010) as follows: (1). Stressors that affect brain development in a stretched individual can lead to psychiatric symptoms. (2) Provide negative examples of interpersonal communication that will shape future behavior. The results of verbal abuse are: (1). There is emotional disturbance in the development of a positive self-concept in overcoming aggressiveness, the development of social relationships with others, including the ability to be confident. (2) Emotional pseudomaturity, some children become aggressive or hostile to adults, while others become withdrawn / away from associations. children become strange behavior, learning difficulties, failing schools, difficulty sleeping and so on. (3) Children who are mistreated feel they are ugly, unloved, unwanted, gloomy and unhappy, unable to enjoy activities and some even try to commit suicide. According to a phenomenological study the experience of verbal violence is feelings of disappointment. Almost all informants stated that the impact of verbal abuse was feelings of disappointment. According to Magnavita et al. (2011) the impact of verbal violence is: Emotional disturbances; Low self-concept; Aggressive; Social relations; Suicide; Another result : The increasing prevalence of verbal violence perpetrated by every group in the digital era, the more unsettling for the community, especially some who are active as social media users. They have become more careful in using social media so as not to come under criticism from netizens. Therefore, in order not to cause more victims of verbal violence, there should be limits or prevention in this behavior. This prevention is none other than to regulate how users of language or communication media limit their curiosity about what they see. Prevention can also be said to be an effort to avoid negative behaviors that arise or arise as a result of the influence of the social, cultural, educational, and family environment.

\section{Efforts to Prevent Verbal Violent Behavior}


In other words, this prevention effort requires serious action from the community itself, teachers or parents. Of course, this must be followed by a high commitment and full awareness of each individual that verbal abuse behavior is very detrimental to himself and others both in terms of mental, moral and character. The efforts to prevent verbal violence, especially in this digital era, include: (1) avoiding hoax news; (2) instilling habits of good behavior from an early age (parents must be careful when speaking in front of their children); (3) making persuasion advertising a form of strengthening social relations; (4) accustom positive criticism; (5) respect the privacy of others; (6) always use communication tools proportionally; (7) maintaining communication ethics; and (8) avoiding racist and racist content.

\section{Conclusion}

Violence is an action that can injure a person physically, mentally, and mentally if it is done continuously. Violence consists of several types, one of which is verbal abuse or emotional violence which is a form of direct and indirect manipulation that occurs in the social, cultural, educational, and family environment. Verbal abuse greatly affects the psychological and mental health of the victim, if when the victim experiences verbal abuse from a young age, it is likely that she will carry the scar until she is an adult. The consequences of verbal abuse in childhood are stressors that affect brain development in a range of individuals, which can cause psychiatric symptoms. Provide negative examples of interpersonal communication that will shape future behavior. Efforts that can be made to prevent verbal violence include avoiding hoax news, instilling habits of good behavior from an early age (parents must be careful when speaking in front of their children),creating related advertisements to strengthen social relations, accustom positive criticism, respect the privacy of others, using communication tools proportionally, maintaining communication ethics, and avoiding racist and racist content.

\section{References}

Bariola, E., Gullone, E., \& Hughes, E. K. (2011). Child and adolescent emotion regulation: The role of parental emotion regulation and expression. Clinical child and family psychology review, 14(2), 198.

Cater, Å. K., Andershed, A. K., \& Andershed, H. (2014). Youth victimization in Sweden: Prevalence, characteristics and relation to mental health and behavioral problems in young adulthood. Child abuse \& neglect, 38(8), 1290-1302.

DeWall, C. N., Anderson, C. A., \& Bushman, B. J. (2011). The general aggression model: Theoretical extensions to violence. Psychology of Violence, 1(3), 245

Finkelhor, D., Turner, H., Hamby, S. L., \& Ormrod, R. (2011). Polyvictimization: Children's Exposure to Multiple Types of Violence, Crime, and Abuse. National survey of children's exposure to violence.

Fontaine, J. R., Scherer, K. R., \& Soriano, C. (Eds.). (2013). Components of emotional meaning: A sourcebook. Oxford University Press.

Hay, C., \& Meldrum, R. (2010). Bullying victimization and adolescent self-harm: Testing hypotheses from general strain theory. Journal of youth and adolescence, 39(5), 446-459.

Henry, J. P., \& Stephens, P. M. (2013). Stress, health, and the social environment: A sociobiologic approach to medicine. Springer Science \& Business Media. 
Hunt, J. (2013). Verbal \& Emotional Abuse (June Hunt Hope for the Heart): Victory Over Verbal and Emotional Abuse. Aspire Press

Livingstone, S., \& Smith, P. K. (2014). Annual research review: Harms experienced by child users of online and mobile technologies: The nature, prevalence and management of sexual and aggressive risks in the digital age. Journal of child psychology and psychiatry, 55(6), 635-654

Martin, G., \& Pear, J. J. (2019). Behavior modification: What it is and how to do it. Routledge

Magnavita, N., \& Heponiemi, T. (2011). Workplace violence against nursing students and nurses: an Italian experience. Journal of nursing scholarship, 43(2), 203-210

Rosenthal, L. J., Byerly, A., Taylor, A. D., \& Martinovich, Z. (2018). Impact and prevalence of physical and verbal violence toward healthcare workers. Psychosomatics, 59(6), 584-590.

Özgüle, M. (2016). Childrens perception of violence in daily life a qualitative analysis of childrens verbal expressions and stories (Doctoral dissertation, İstanbul Bilgi Üniversitesi)

Teicher, M. H., Samson, J. A., Sheu, Y. S., Polcari, A., \& McGreenery, C. E. (2010). Hurtful words: association of exposure to peer verbal abuse with elevated psychiatric symptom scores and corpus callosum abnormalities. American journal of psychiatry, 167(12), 1464-1471 